\title{
Localization of $\mathrm{Ca}^{2+}$-dependent conformational changes of calretinin by limited tryptic proteolysis
}

\author{
Jacek KUŹNICKI, ${ }^{\star} \ddagger$ Tao-Chin L. WANG, ${ }^{\star}$ Brian M. MARTIN, $†$ Lois WINSKY ${ }^{\star}$ and David M. JACOBOWITZ \\ *Laboratory of Clinical Science and fClinical Neurosciences Branch, National Institute of Mental Health, Bethesda, MD 20892, U.S.A.
}

Calretinin is an EF-hand $\mathrm{Ca}^{2+}$-binding protein expressed predominantly in some neurons. We have found that the tryptic digestion pattern of rat recombinant calretinin depends on $\mathrm{Ca}^{2+}$ concentration as determined by SDS/PAGE, amino-acid-sequence analysis and electrospray-ionization MS. $\mathrm{Ca}^{2+}$-saturated calretinin was cleaved between amino acids 60 and 61 to yield two fragments, which accumulated during cleavage. Small amounts of the larger fragment (amino acid residues 61-271) were further cleaved from the $\mathrm{C}$-terminal end. $\mathrm{Ca}^{2+}$-free calretinin was also cleaved between residues 60 and 61 ; however, under the latter conditions the fragment 61-271 was further cleaved from the $\mathrm{N}$-terminal end. Native rat calretinin was cleaved by trypsin in a similar $\mathrm{Ca}^{2+}$-dependent fashion. All identified fragments of recombinant calretinin bound ${ }^{45} \mathrm{Ca}^{2+}$ on nitrocellulose filters, although to a different extent. The 61-271 fragment was released by EGTA from an octyl-agarose column in a manner similar to intact calretinin, while fragment 61-233 was not eluted by EGTA. These observations show that there are trypsin cleavage sites in calretinin that are available regardless of $\mathrm{Ca}^{2+}$ binding, other sites that are completely protected against trypsin on $\mathrm{Ca}^{2+}$. binding and sites which become partially available on $\mathrm{Ca}^{2+}$ binding. Together these data show that calretinin changes its conformation on $\mathrm{Ca}^{2+}$ binding and identify the regions which are exposed in apo and $\mathrm{Ca}^{2+}$-bound form.

\section{INTRODUCTION}

Calretinin is a $\mathrm{Ca}^{2+}$-binding protein present mainly in a variety of brain neurons [1-6]. Recently calretinin has also been identified in interstitial cells of rat ovary [7], enteric nervous system [8,9] and in Leydig cells of testis [10], as well as in human cancer cells [11] and in early embryonic development [12]. Calretinin is a member of the EF-hand superfamily which includes, for example, calbindin D28k, calmodulin, troponin C, parvalbumin and $\mathbf{S 1 0 0}$ proteins (reviewed in [13-16]). Calretinin shows most similarity to calbindin D28k, sharing $58 \%$ identical residues $[1,17,18]$. Both proteins contain six putative EF-hand motifs (although the sixth is aberrant), each of which consists of a helix-loop-helix structure and represents potential $\mathrm{Ca}^{2+}$-binding sites (reviewed in $[19,20])$. The function of calretinin is not yet known. Its predominantly cytosolic distribution and ability to bind $\mathrm{Ca}^{2+}$ ions would be consistent with a role in neurotransmission. This role could involve interaction with other proteins, facilitating $\mathrm{Ca}^{2+}$ diffusion, or providing short-term buffering of local $\mathrm{Ca}^{2+}$ concentrations in cytosol. $\mathrm{A} \mathrm{Ca}^{2+}$-buffering role has been previously suggested for calbindin D28k and parvalbumin (reviewed in $[21,22])$, but a neuroprotective action against $\mathrm{Ca}^{2+}$ overload for these $\mathrm{Ca}^{2+}$-binding proteins has not been proved (reviewed in $[16,23])$. On the basis of the low evolutionary rate of calretinin and the strong sequence conservation with calbindin D28k in EFhand regions and sequences that follow the even-numbered EF-hands, it has been suggested that calretinin may do more than simply bind $\mathrm{Ca}^{2+}$ for the purpose of lowering cytosolic concentrations $[17,20,24]$. Despite many studies of the distribution of calretinin in tissues, information about its biochemical properties is very limited. Calretinin's electrophoretic properties and its ability to bind $\mathrm{Ca}^{2+}$ were shown by several authors $[1,2,24,25]$.
Calretinin was found to bind at least four $\mathrm{Ca}^{2+}$ ions with a $K_{\mathrm{d}}$ between 0.3 and $0.5 \mu \mathrm{M}$ [24,25]. Recently, several groups have developed methods for the production and purification of recombinant calretinin from Escherichia coli, which will permit a structure-function analysis of this protein [17,24,25]. Using rat recombinant calretinin we have initiated studies of structure, conformational changes and a search for possible calretinin targets. Work on the hydrophobic properties and subcellular distribution of calretinin has been presented [26,27]. The aim of the present work was to examine the effect of $\mathrm{Ca}^{2+}$ binding on the calretinin structure, using limited proteolysis by trypsin. A different cleavage pattern was generated by $\mathrm{Ca}^{2+}$-free and $\mathrm{Ca}^{2+}$ bound forms of calretinin, indicating a characteristic conformational change on $\mathrm{Ca}^{2+}$ binding. The identification of cleavage sites by MS and amino-acid-sequence analysis allowed us to identify specific regions which were exposed in the apo and $\mathrm{Ca}^{2+}$ bound form. The analysis of proteolytic fragments also allowed us to locate a region which may be responsible for the $\mathrm{Ca}^{2+}$ dependent hydrophobicity of calretinin. These studies provide insights into the molecular design of this protein and its role as a $\mathrm{Ca}^{2+}$ buffer and/or a $\mathrm{Ca}^{2+}$-dependent activator.

\section{EXPERIMENTAL}

\section{Purification of rat calretinin}

Rat calretinin was expressed in $E$. coli as a fusion protein with glutathione S-transferase and purified as described by Strauss et al. [25]. Essentially the fusion protein bound to glutathioneSepharose was cleaved by thrombin to yield calretinin. Separation from thrombin was achieved using $\mathrm{Ca}^{2+}$-dependent elution of calretinin from DEAE-cellulose. If necessary, an additional purification step was performed using an FPLC system and a 
Superose 12 column (Pharmacia) equilibrated with $150 \mathrm{mM}$ $\mathrm{NaCl} / 1 \mathrm{mM}$ EGTA/50 mM Tris, $\mathrm{pH}$ 8.0. Native rat calretinin was purified from the cerebellum of male rats (Sprague-Dawley; Zivic-Miller, Zelienope, PA, U.S.A.) weighing 200-350 g. Fresh rat cerebella were homogenized $\left(4^{\circ} \mathrm{C}\right)$ in $10 \mathrm{vol}$. of $0.32 \mathrm{M}$ sucrose $/ 5 \mathrm{mM}$ Hepes ( $\mathrm{pH} 7.4$ ) $/ 0.1 \mathrm{mM} \mathrm{CaCl} / 25 \mu \mathrm{g} / \mathrm{ml}$ leupeptin, and subjected to centrifugation at $800 \mathrm{~g}$ for $10 \mathrm{~min}$. The final soluble extract (cerebellar cytosol) was obtained by ultracentrifugation of the supernatant at $165000 \mathrm{~g}$ for $1 \mathrm{~h}$. Aliquots were stored $\left(-80^{\circ} \mathrm{C}\right)$ until use. Native rat calretinin was bound to DEAE-cellulose equilibrated with $20 \mathrm{mM} \mathrm{NaCl} / 1 \mathrm{mM}$ EGTA/50 mM Tris, pH 8.0. It was then eluted with $20 \mathrm{mM}$

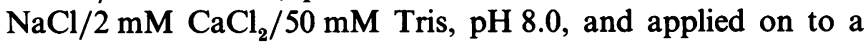
Superose 12 column as described above for recombinant calretinin. The fractions containing calretinin were desalted on PD10 columns (Pharmacia) equilibrated with $50 \mathrm{mM} \mathrm{NH}_{4} \mathrm{HCO}_{3}$ and concentrated by partial freeze-drying. Protein concentration was measured using the Bio-Rad protein assay with BSA as a standard.

\section{Tryptic digestion of rat calretinin}

Rat recombinant calretinin $(0.18-0.31 \mathrm{mg} / \mathrm{ml})$ or native calretinin $(0.1 \mathrm{mg} / \mathrm{ml})$ were incubated $\left(37^{\circ} \mathrm{C}\right)$ with sequencinggrade trypsin (Boehringer-Mannheim Biochemica) at an enzyme/substrate ratio of $1: 100(\mathrm{w} / \mathrm{w})$ in the presence of $150 \mathrm{mM}$ $\mathrm{NaCl} / 50 \mathrm{mM}$ Tris, $\mathrm{pH} 8.0$, and either $0.1 \mathrm{mM} \mathrm{CaCl}$ or $1 \mathrm{mM}$ EGTA. The digestion was stopped at various times by transferring sample aliquots to tubes containing soybean trypsin inhibitor (Sigma) (enzyme/inhibitor ratio 1:2, w/w). The fragments generated from calretinin digestion were subsequently analysed by SDS/PAGE, and either stained with silver or transferred on to nitrocellulose filters (for ${ }^{45} \mathrm{Ca}^{2+}$ overlay and immunoblotting) or poly(vinylidene difluoride (PVDF) membranes (for amino acid sequencing).

\section{${ }^{45} \mathrm{Ca}^{2+}$ overlay and immunoblotting}

SDS/PAGE was performed on $15 \%$ precast gels (Bio-Rad) in Tris/glycine buffer, $\mathrm{pH}$ 8.3. The $\mathrm{Ca}^{2+}$ binding of calretinin fragments was analysed on nitrocellulose filters $(0.45 \mu \mathrm{m}$ pore size; Schleicher and Schuell) using the method described by Maruyama et al. [28]. Immunoblotting was performed using a chemiluminescence kit (Kirkegaard and Perry Laboratories, Gaithersburg, MD, U.S.A) with anti-calretinin serum diluted $1: 7000$.

\section{Amino-acld-sequence analysis}

Proteins were transferred from SDS/page gels on to PVDF membrane (Millipore). The membranes were stained with $0.1 \%$ Coomassie Blue in 50\% methanol, destained in 50\% methanol, and washed in deionized water. The protein bands were excised from the membrane and sequenced using an Applied Biosystems $470 \mathrm{~A}$ gas-phase sequencer equipped with a model $120 \mathrm{~A}$ on-line phenylthiohydantoin analyser. Four to ten cycles were run for each peptide band.

\section{Electrospray $\cdot$ Ionization (ESI) MS}

Analyses of native calretinin, recombinant calretinin and mixtures of tryptic fragments were performed by ESI-MS using a Hewlett-Packard electrospray source mounted on an HewlettPackard 5989 mass spectrometer. The capillary, end plate and cylinder potentials were set at $-4500,-3500$ and $-3000 \mathrm{~V}$ respectively. The capillary exit potential was set at $200 \mathrm{~V}$. The analyses of tryptic digests of recombinant calretinin $(83.3 \mu \mathrm{M})$ by MS were performed in $50 \mathrm{mM}\left(\mathrm{NH}_{4}\right)_{2} \mathrm{CO}_{3}$, since Tris is incompatible with ESI-MS analyses. The digestions were stopped at $50 \mathrm{~min}$ (in the presence of $\mathrm{Ca}^{2+}$ ) and $20 \mathrm{~min}$ (in the presence of EGTA) by the addition of the electrospray solvent mixture and analysed immediately.

\section{Hydrophobic chromatography using centrifugal filtration}

All steps were performed at room temperature as previously described [26]. Suspensions ( $0.2 \mathrm{ml}$ each) of octyl-agarose (Sigma; CNBr-activated; O-6376) were added to Ultrafree-MC filter units $(0.45 \mu \mathrm{m}$ pore size); Millipore (UFC3 OHV 00) sitting inside $1.5 \mathrm{ml}$ Eppendorf collection tubes. The suspensions were centrifuged for $10 \mathrm{~s}$ in a Tomy HF-120 instrument, and the fluid present in the collecting tubes was discarded. The resin in each sample was washed five times by addition of $0.2 \mathrm{ml}$ of the appropriate buffer, mixed, centrifuged, and the fluid present in the collecting tubes was removed. Samples of recombinant calretinin, or calretinin tryptic fragments, were equilibrated with initial resin buffer on Sephadex G-25 column (PD-10 or NAP-5; Pharmacia) and added to the resin in $0.2 \mathrm{ml}$ portions $(60-105 \mu \mathrm{g}$ of recombinant protein or $50 \mu \mathrm{g}$ of tryptic fragments). The contents were then vortex-mixed and incubated for $10 \mathrm{~min}$. Filter units were centrifuged, and the fluid containing the unbound fractions was collected. The samples of resin were washed twice with $0.2 \mathrm{ml}$ of the appropriate solutions (the second wash contained practically no protein), and an elution buffer containing $2 \mathrm{mM}$ EGTA, and then $1 \%$ SDS in water $(0.2 \mathrm{ml})$, were sequentially applied to the resin. Eluates were collected by centrifugation after each addition. The applied, unbound and eluate fractions were examined on SDS/PAGE gels stained with silver.

\section{RESULTS}

\section{Tryptic digestion of rat recombinant calretinin}

Examinations of proteins separated on SDS/PAGE gels and stained with silver (not shown) or transferred to blots and stained with Ponceau Red (Figure 1) revealed that the pattern of tryptic digestion of calretinin was dependent on the presence of $\mathrm{Ca}^{2+}$. Calretinin saturated with $\mathrm{Ca}^{2+}$ yielded two major fragments which could be seen after $1 \mathrm{~min}$ exposure to trypsin. The larger fragment was partially cleaved at additional sites to yield three smaller peptides. Apo-calretinin was initially more resistant to tryptic digestion than the $\mathrm{Ca}^{2+}$-bound form, since after $20 \mathrm{~min}$ of incubation with trypsin, undigested apo-calretinin was still present, while $\mathrm{Ca}^{2+}$-bound calretinin was totally cleaved (Figure 1). However, more fragments of lower molecular masses were formed from apoprotein than from $\mathrm{Ca}^{2+}$-bound calretinin (Figure 1; $20 \mathrm{~min}$ ). Native rat calretinin was cleaved by trypsin in a similar $\mathrm{Ca}^{2+}$-dependent fashion (results not shown).

\section{Ability of tryptic fragments to bind ${ }^{45} \mathrm{Ca}^{2+}$}

Major calretinin tryptic fragments were labelled either $\mathrm{Cl}-\mathrm{C5}$ (Figure 1, top) or E1-E6 (Figure 1, bottom) after digestion of calretinin in the presence of $\mathrm{Ca}^{2+}$ and of the apoprotein respectively. The calretinin fragments generated by trypsin were separated by gel electrophoresis, transferred to nitrocellulose filters, and incubated with ${ }^{45} \mathrm{Ca}^{2+}$. Autoradiograms of the blots revealed that all fragments stained with Ponceau Red were able to bind $\mathrm{Ca}^{2+}$ (Figure 1). The amount of radioactivity associated with each band varied, but binding was detectable even for small fragments such as C5 and E6. A strong signal, similar to that of 

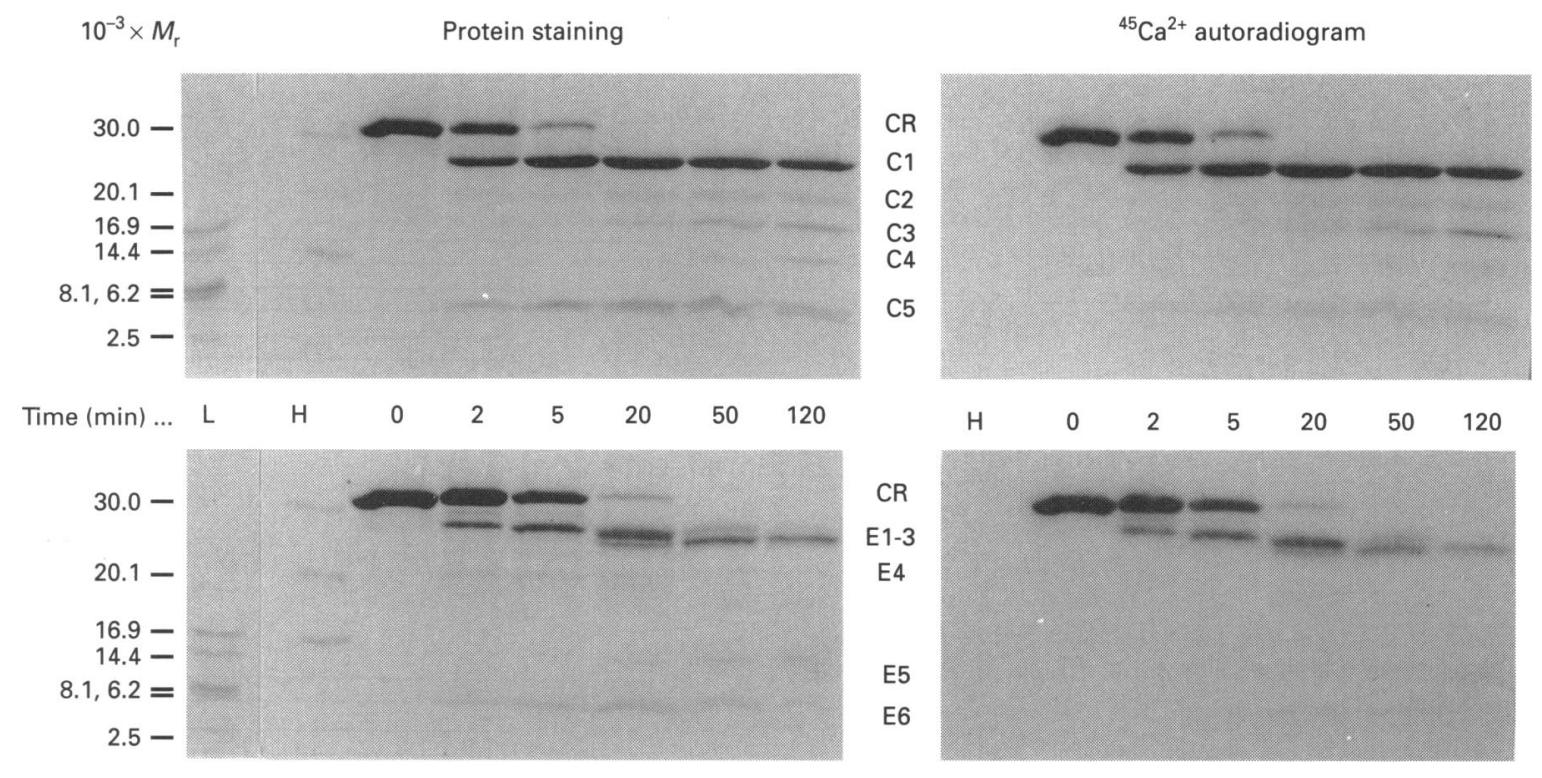

Figure 1 Digestion of recombinant calretinin (CR) by trypsin at indicated time points (min) in the presence of Ca ${ }^{2+}$ (top) or EGTA (bottom)

Samples were separated by SDS/15\%-PAGE and blotted on to nitrocellulose. Proteins were stained with Ponceau Red ('Protein staining') and next incubated with ${ }^{45} \mathrm{Ca}^{2+}\left({ }^{45} \mathrm{Ca}^{2+}\right.$ autoradiogram'). $\mathrm{M}_{\mathrm{r}}$, molecular masses of markers: $\mathrm{H}, 30,20.1$ and $16.9 \mathrm{kDa} ; \mathrm{L}, 16.9,14.4,8.1,6.2$ and $2.5 \mathrm{kDa}$. Calretinin fragments generated in the presence of $\mathrm{Ca}^{2+}$ are labelled $\mathrm{C1}-\mathrm{C} 5$ (see Table 1 ) and those generated in the presence of EGTA are labelled E1-E6 (Table 1).

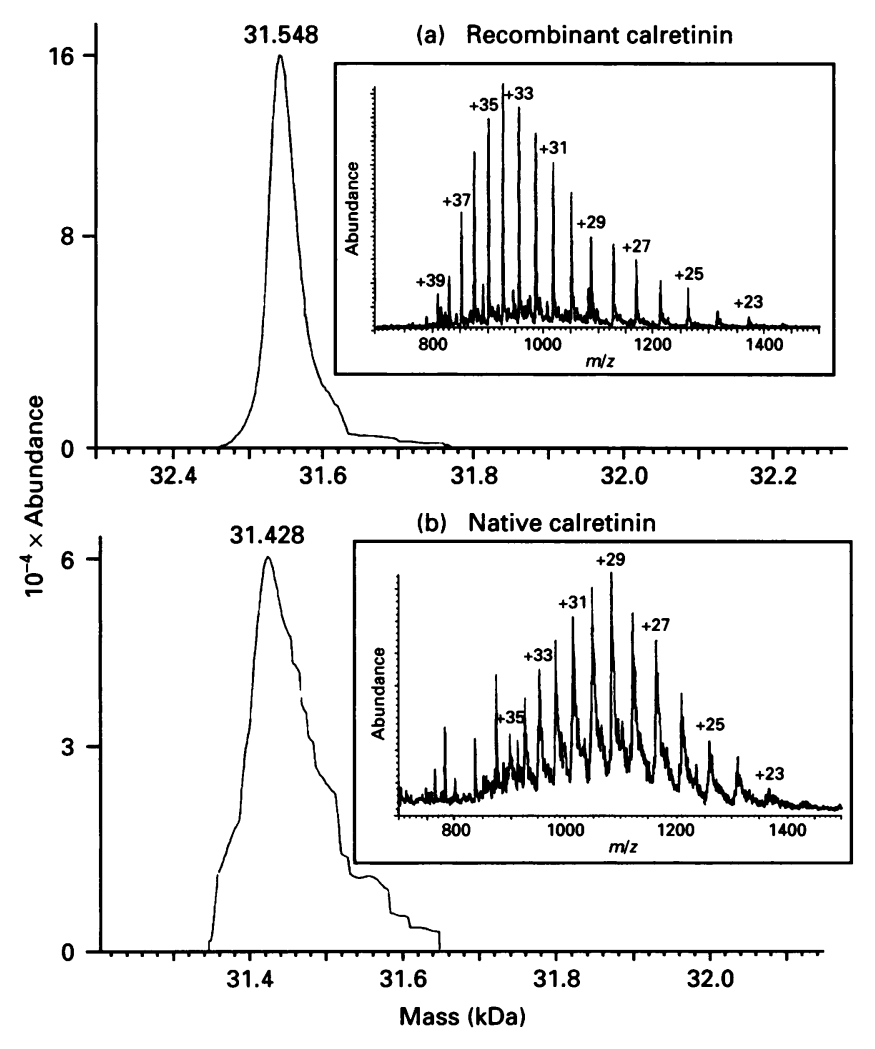

Figure 2 Spectra obtained by ESI-MS before (insets) and after deconvolution

Recombinant rat calretinin $(1.3 \mu \mathrm{M})(\mathbf{a})$; native calretinin $(<1 \mu \mathrm{M})(\mathbf{b})$. Alternate charge states are labelled and indicate that recombinant calretinin prefers a +34 charge state, whereas native calretinin exhibits a +29 charge-state maximum. the uncleaved protein, was observed for the $\mathrm{C} 1$ fragment formed in the presence of $\mathrm{Ca}^{2+}$ (Figure 1).

\section{MS analysis of calretinin}

Figure 2 shows the computer-deconvoluted mass spectra of recombinant (Figure 2a) and native (Figure $2 b$ ) calretinin. The ESI mass spectra are shown in the insets to Figure 2, with the charge states of the ions labelled. The best spectrum of recombinant calretinin was obtained after 20-200-fold dilution of the stock sample $(83.3 \mu \mathrm{M})$ in acetonitrile/water/acetic acid (99:99:2, by vol.) The mass measurement accuracy over this concentration range was found to be within $0.006 \%$ (i.e. \pm 1.9 atomic mass units). The ESI mass spectrum for native calretinin $(<1 \mu \mathrm{M})$ in the same solvent mixture is shown in the inset of Figure 2(b). The deconvoluted mass spectrum shows a molecular mass of $31428 \mathrm{Da}$. However, the charge state ions exhibit broader peak widths than in the spectrum of recombinant calretinin.

\section{Identification of tryptic cleavage sites}

Amino-acid-sequence analysis (not shown) enabled us to determine the $\mathrm{N}$-terminal ends of the calretinin fragments which were stained on the blots (Figure 1). These data were useful in identifying cleavage sites which yielded $\mathrm{Cl}$ and $\mathrm{C} 5$ fragments. The fragments $\mathrm{C} 2-\mathrm{C} 4$ had the same $\mathrm{N}$-terminal end as $\mathrm{C} 1$, but a different molecular mass as estimated by their mobility on SDS/PAGE. This indicates that the smaller fragments were generated from bigger ones by removing the $\mathrm{C}$-terminal amino acids. In contrast, except for $\mathrm{E} 1$, which had the same $\mathrm{N}$-terminal end as $\mathrm{Cl}$, all other fragments generated from the apo form had different $\mathrm{N}$-terminal sequences. To identify the $\mathrm{C}$-termini of all fragments, their exact masses were measured by ESI-MS. The spectrum of the $\mathrm{Ca}^{2+}$ digest of recombinant calretinin was 


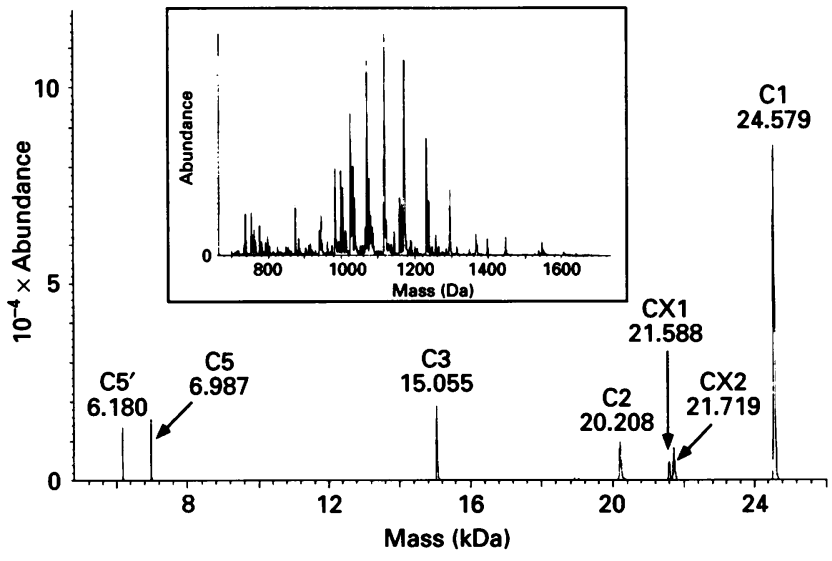

Figure 3 Spectrum of calretinin fragments generated by trypsin digestion (50 min) in the presence of $\mathrm{Ca}^{2+}$ (see Figure 1 and Table 1) before (inset) and after deconvolution

The sample $(2.6 \mu \mathrm{M})$ did not contain soybean trypsin inhibitor.

Table 1 Molecular mass and amino acid composition of rat calretinin and its tryptic fragments

\begin{tabular}{|c|c|c|c|}
\hline $\begin{array}{l}\text { Calretinin or } \\
\text { fragment }\end{array}$ & $\begin{array}{l}\text { Molecular mass (Da) } \\
\text { determined by MS }\end{array}$ & $\begin{array}{l}\text { Calculated from } \\
\text { amino acid } \\
\text { sequence }\end{array}$ & $\begin{array}{l}\text { Amino acid } \\
\text { sequence }\end{array}$ \\
\hline Native & $31428-31431$ & $31404^{*}$ & $1-271$ \\
\hline Recombinant & $31547-31550$ & 31549 & Gly-Ser-1-271 \\
\hline \multicolumn{4}{|c|}{$\begin{array}{l}\text { Tryptic fragment } \\
\text { of recombinant }\end{array}$} \\
\hline C1 & 24579 & 24579 & $61-271$ \\
\hline C2 & 20208 & 20210 & $61-233$ \\
\hline C3 & 15055 & 15058 & $61-189$ \\
\hline C4 & ND & 12888 & $\uparrow 61-170$ \\
\hline C5 & 6987 & 6988 & Gly-Ser-1-60 \\
\hline$C 5^{\prime}$ & 6180 & 6181 & Gly-Ser-1-52 \\
\hline E1 & 24619 & 24579 & $\dagger 61-271$ \\
\hline E2 & ND & 23801 & $\dagger 68-271$ \\
\hline E3 & 23539 & 23542 & $70-271$ \\
\hline E4 & 22879 & 22878 & $75-271$ \\
\hline E5 & 10834 & 10835 & $179-271$ \\
\hline E6 & 6987 & 6988 & Gly-Ser-1-60 \\
\hline$E 6^{\prime}$ & ND & 6181 & †Gly-Ser-1-52 \\
\hline cX1‡ & 21588 & 21589 & $61-244$ \\
\hline $\mathrm{c} \times 2$ & 21719 & 21717 & $61-245$ \\
\hline EX1‡ & 23687 & 23686 & $27-230$ \\
\hline EX2 & 16209 & 16204 & $40-178$ \\
\hline EX3 & 15053 & 15058 & $61-189$ \\
\hline EX4 & 11909 & 11911 & $61-161$ \\
\hline
\end{tabular}

* With methionine.

$\dagger$ means a possible calcium adduct formation, or when mass of the fragment was not detected (ND).

$\ddagger C X$ and EX refer to the fragments which were not detected on gels and blots.

obtained after 32-fold dilution of the digestion mixture (inset to Figure 3). The spectrum from the EGTA digest was more complicated than $\mathrm{Ca}^{2+}$-digest spectrum and required several processes of deconvolution (not shown). The molecular masses of calretinin fragments generated both in the presence of $\mathrm{Ca}^{2+}$ (Figure 3) or EGTA (not shown) are shown in Table 1. These (a) $\mathrm{Ca}^{2+}$

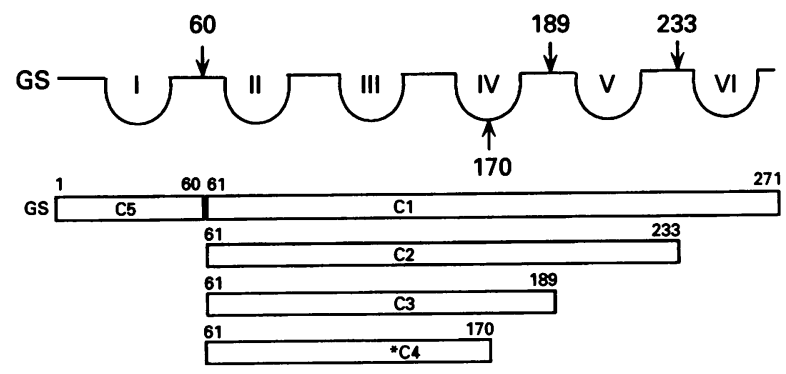

(b) EGTA

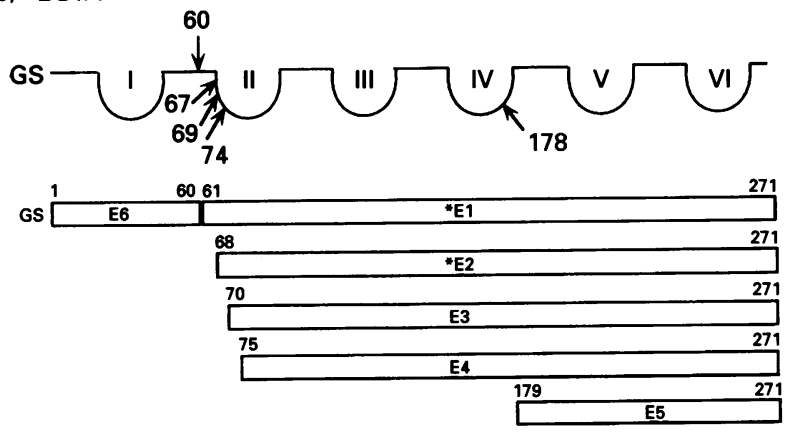

Figure 4 Schematic structure of calretinin and its major tryptic fragments generated in the presence of $\mathrm{Ca}^{2+}$ (a) and in the absence of $\mathrm{Ca}^{2+}$ (EGTA) (b)

The tryptic cleavage sites are shown by arrows. Arabic numbers refer to the position of lysine or arginine at the cleavage sites, and Roman numerals show EF-hand motifs. Asterisks indicate the fragments whose mass determinated by MS did not match the mass derived from the amino acid sequence.

masses were compared with the theoretical masses of the fragments having known $\mathrm{N}$-terminal ends and possible $\mathrm{C}$-terminal ends. The sequences that matched the experimentally determined molecular masses revealed some unknown cleavage sites and confirmed those identified by amino acid sequencing (Table 1). These data enabled us to identify trypsin cleavage sites of $\mathrm{Ca}^{2+}$ bound and apo-calretinin as summarized in Figure 4 . The bond between amino acid residues 60 and 61 was most readily cleaved by trypsin in both the presence and absence of $\mathrm{Ca}^{2+}$. Thus fragments $\mathrm{Cl}$ and $\mathrm{E} 1$ were equivalent, as were $\mathrm{C} 5$ and $\mathrm{E} 6$. The 60-61 site is located in the region connecting EF-hand segments $\mathrm{I}$ and II. The $\mathrm{Cl}$ fragment (61-271) accumulated in the presence of $\mathrm{Ca}^{2+}$, even though it was susceptible to further partial cleavage at sites 189-190 (the region connecting EF-hand motifs IV and V), 233-234 (the region connecting EF-hand motifs V and VI) and possibly between 170 and 171 (Figure 4). This cleavage yielded fragments $\mathrm{C} 3, \mathrm{C} 2$ and $\mathrm{C} 4$ respectively. It is clear that the C-terminal half of the 61-271 fragment $(\mathrm{C} 1)$ became partly exposed to trypsin in the presence of $\mathrm{Ca}^{2+}$ ions, whereas the $\mathrm{N}$ terminal end was very resistant to proteolysis.

When the $\mathrm{Ca}^{2+}$-free 61-271 (E1) fragment was incubated with trypsin different sites became exposed and cleaved than those seen for the $\mathrm{Ca}^{2+}$-bound equivalent (C1). Three of the most susceptible sites $(67-68,69-70,74-75)$ were located at the $\mathrm{N}$ terminal end of this fragment, i. e. in the $\mathrm{N}$-terminal $\alpha$-helix of the EF-hand II, whereas the fourth site (178-179) was located in the C-terminal $\alpha$-helix of the EF hand IV (Figure 4). Thus fragments E2-E4 were generated by cleavage at sites which were not exposed in the presence of $\mathrm{Ca}^{2+}$ (Figure 4). Additional 
(a)

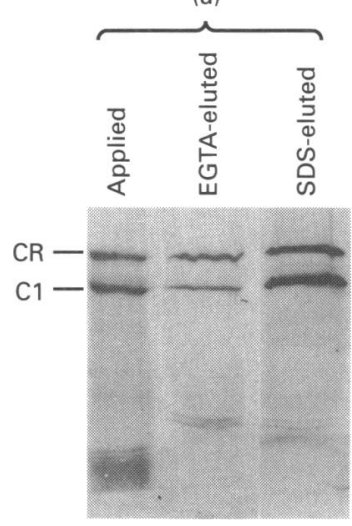

(b)

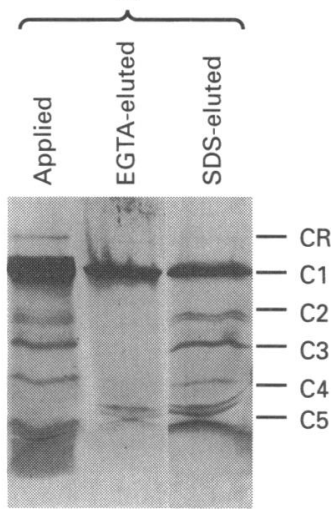

Figure 5 Hydrophobic interaction of recombinant calretinin (CR) and tryptic fragments of calretinin with octyl-agarose

The fragments generated from $\mathrm{Ca}^{2+}$-bound calretinin after 20 (a) and 60 (b) min incubation with trypsin were added to octyl-agarose ('Applied'). Calretinin and all fragments (C1-C5, see Table 1) bound to the resin. The EGTA-containing solution eluted calretinin, $\mathrm{C} 1$ and $\mathrm{C} 5$ ('EGTA-eluted'), whereas the SDS-containing solution eluted C2, C3, C4 and the remainder of calretinin, C1 and C5 ('SDS-eluted').

cleavage sites found by MS analysis also were different in the absence and presence of $\mathrm{Ca}^{2+}$ (Table 1).

\section{$\mathrm{Ca}^{2+}$-dependent binding of tryptic fragments to octyl-agarose}

Intact calretinin has been shown to exhibit complex hydrophobicity. It binds to hydrophobic resins such as octyl-agarose in the presence of $\mathrm{Ca}^{2+}$, but is only partly released when the $\mathrm{Ca}^{2+}$ concentration is lowered by EGTA or EDTA [26]. All fragments generated by tryptic digestion in the presence of $\mathrm{Ca}^{2+}$ after $20 \mathrm{~min}$ (Figure 5a) or $60 \mathrm{~min}$ (Figure 5b) bound to octyl-agarose. On addition of the EGTA-containing solution, less than half of the recombinant calretinin and a comparable amount of the $\mathrm{Cl}$ fragment generated after 20 min digestion were released from the resin (Figure 5a). However, the smaller fragments (C2-C4) generated during $1 \mathrm{~h}$ digestion were not eluted by EGTA, but were released from the resin by the addition of SDS (Figure 5b). These results indicate that fragment 61-271 has $\mathrm{Ca}^{2+}$-dependent hydrophobic properties similar to those of intact protein, while fragment consisting of amino acids between 61 and 233 exhibit primarily $\mathrm{Ca}^{2+}$-independent hydrophobicity. Therefore it may be concluded that the region between amino acid residues 234 and 271, which encodes EF-hand motif VI, might be important for $\mathrm{Ca}^{2+}$-dependent elution from the hydrophobic resin. However, it is not clear if this region has a $\mathrm{Ca}^{2+}$-sensitive hydrophobic patch itself (EF-hand VI is aberrant and should not bind $\mathrm{Ca}^{2+}$ ) or if it interacts with another part of the molecule to induce $\mathrm{Ca}^{2+}$ sensitive hydrophobicity.

\section{DISCUSSION}

The studies described here provide strong evidence that calretinin changes conformation on $\mathrm{Ca}^{2+}$ binding and give some insights into its structure. Rat calretinin has 26 lysine and nine arginine residues which are potential cleavage sites for trypsin. Among these, only one, a bond between residues 60 and 61 , is preferentially cleaved by this proteinase. This bond is cleaved in both $\mathrm{Ca}^{2+}$-free and $\mathrm{Ca}^{2+}$-bound forms of the protein, although at a slightly lower rate in the $\mathrm{Ca}^{2+}$-free form. These observations suggest that the linking region between EF-hand motifs I and II of calretinin is exposed regardless of $\mathrm{Ca}^{2+}$ binding. However, different dynamics seems to occur in this region on $\mathrm{Ca}^{2+}$ binding, resulting in different rates of cleavage at this site. As in calbindin D28k, the linking region between EF-hand motifs I and II of calretinin is longer than the linking regions connecting other EFhand motifs $[1,29]$.

A significant effect of $\mathrm{Ca}^{2+}$ binding is observed on the tryptic digestion pattern of the calretinin fragment 61-271. In general, $\mathrm{Ca}^{2+}$ bound to this fragment provides resistance to cleavage, since it accumulates during long exposure to trypsin. The $\mathrm{N}$ terminal half of this fragment is resistant to trypsin, but some regions in the $\mathrm{C}$-terminal half are not resistant. It should be pointed out that two out of three secondary digestion sites of $\mathrm{Ca}^{2+}$-bound calretinin are not in the $\mathrm{Ca}^{2+}$-binding loops, but rather in the linking regions connecting EF-hand motifs. Therefore, the different pattern of digestion cannot be explained by the direct effect of $\mathrm{Ca}^{2+}$; rather it should be explained by a $\mathrm{Ca}^{2+}$. induced conformational change.

In a $\mathrm{Ca}^{2+}$-free conformation, fragment $61-271$ was cleaved predominantly at the $\mathrm{N}$-terminal end. Three cleavage sites were located in the N-terminal $\alpha$-helix of EF-hand motif II and one in the C-terminal $\alpha$-helix of EF-hand motif IV. These observations indicate that dissociation of $\mathrm{Ca}^{2+}$ from calretinin exposes different regions to trypsin than those which were exposed in the $\mathrm{Ca}^{2+}$. bound state. Moreover, the fact that EF-hand site II shows $\mathrm{Ca}^{2+}$. sensitive tryptic degradation after separation from the EF-hand site I, may suggest that this site is capable of binding $\mathrm{Ca}^{2+}$, as proposed by Parmentier [30], and in contrast with the properties of this site in calbindin D28k. Recent data showing that calretinin binds more $\mathrm{Ca}^{2+}$ than calbindin D28k, is consistent with these observations [24].

The spectrum of native calretinin exhibits broad peaks which could affect the accuracy of the deconvoluted mass spectrum shown in Figure 2(b). The molecular mass of native calretinin obtained by ESI-MS is 31428 . Since the N-terminal end of this protein is blocked, as found by amino-acid-sequence analysis, this value includes the mass of the blocking group. The theoretical mass calculated from the amino acid sequence of rat native protein is 31404 (if the initiator methionine is present), 31447 (if such a methionine is acetylated), or 31315 (if N-terminal alanine is acetylated and methionine is removed). Since these values do not match the mass obtained experimentally, we cannot say what is the N-terminal end of native rat calretinin and how it is modified. However, the $\mathrm{N}$-terminal residues and post-translational modification have no effect on $\mathrm{Ca}^{2+}$-dependent behaviour of calretinin as indicated by the similar proteolytic cleavage (the present work), $\mathrm{Ca}^{2+}$ binding [25] and hydrophobicity [26] of native and recombinant proteins. Calbindin D28k was reported to be acetylated at the $\mathrm{N}$-terminal alanine [31]. Despite the accumulation of a large amount of data on the tissue- and cellspecific distribution of calretinin [1,3-8,10-12], little is known about the function of this protein. It is possible that calretinin may act as a $\mathrm{Ca}^{2+}$-buffer protecting cells against $\mathrm{Ca}^{2+}$ overload, as was suggested for calbindin D28k $[21,22,32,33]$. On the other hand, it has also been speculated that calretinin may do more than simply bind $\mathrm{Ca}^{2+}$ ions $[16,17,20,23,24]$, although there is no experimental evidence to support this hypothesis and no other function was proposed. The ability of calretinin to change conformation on $\mathrm{Ca}^{2+}$ binding (as evidenced by $\mathrm{Ca}^{2+}$-dependent susceptibility of calretinin to trypsin shown in the present study), and the existence of specific hydrophobic site(s) which are sensitive to $\mathrm{Ca}^{2+}$ (as shown by $\mathrm{Ca}^{2+}$-dependent elution from hydrophobic resins) [26], show that calretinin shares some of the properties of calmodulin, a $\mathrm{Ca}^{2+}$-dependent activator (reviewed 
in [34-36]). These observations allow us to speculate that calretinin may function not only by $\mathrm{Ca}^{2+}$-buffering, but also, like calmodulin, by hydrophobic interactions with as-yet-unidentified targets. The recent analysis of calretinin distribution in rat cerebellum suggests that such targets may exist in membrane preparations [27].

We thank Dr. S. P. Markey for his suggestions and support, B. Teets and J. Lau for technical support, and Hewlett-Packard for the extended loan of a 5989 ESI mass spectrometer. We also thank Dr. K. I. Strauss for providing calretinin plasmid, Dr. Z. Grabarek for his comments on the manuscript before its submission and $\mathrm{Q}$. Ha for her technical assistance.

\section{REFERENCES}

1 Rogers, J. H. (1987) J. Cell Biol. 105, 1343-1353

2 Winsky, L., Nakata, H., Martin, B. M., and Jacobowitz, D. M. (1989) Proc. Natl. Acad. Sci. U.S.A. 86, 10139-10143

3 Arai, R., Winsky, L., Arai, M. and Jacobowitz, D. M. (1991) J. Comp. Neurol. 310, $21-44$

4 Jacobowitz, D. M. and Winsky, L. (1991) J. Comp. Neurol. 304, 198-218

5 Resibois, A. and Rogers, J. H. (1992) Neuroscience 51, 843-865

6 Winsky, L., Montpied, P., Arai, R., Martin, B. M. and Jacobowitz, D. M. (1992) Neuroscience 50, 181-196

7 Pohl, V., Van Rampelbergh, J., Mellaert, S., Parmentier, M. and Pochet, R. (1992) Biochim. Biophys. Acta 1160, 87-94

8 Brookes, S. J., Steele, P. A. and Costa, M., (1991) Cell Tissue. Res. 263, 471-481

9 Isaacs, K., Winsky, L., Strauss, K. I. and Jacobowitz, D. M. (1995) Cell Tiss. Res., in the press

10 Strauss, K. I., Isaacs, K., Ha, Q. and Jacobowitz, D. M. (1994) Biochem. Biophys. Acta $1219,435-440$

11 Gotzos, V., Schwaller, B., Hetzel, N., Bustos-Castillo, M. and Celio, M. R. (1992) Exp. Cell. Res. 202, 292-302
12 Kiraly, E. and Celio, M. R. (1992) Brain Res. Dev. Brain. Res. 70, 149-152

13 Persechini, A., Moncrief, N. D. and Kretsinger, R. H. (1989) Trends Neurosci. 12 $462-467$

14 Strynadka, N. C. J. and James, M. N. G. (1989) Annu. Rev. Biochem. 58, 951-998

15 Baimbridge, K. G., Celio, M. R. and Rogers, J. H. (1992) Trends Neurosci. 15, 303-308

16 Andressen, C., Blumcke, I. and Celio, M. R. (1993) Cell Tissue Res. 271, 181-208

17 Parmentier, M. and Lefort, A. (1991) Eur. J. Biochem. 196, 79-85

18 Strauss, K. I. and Jacobowitz, D. M. (1993) Neurochem. Int. 22, 541-546

19 Kretsinger, R. H. (1987) Cold Spring Harbor Symp. Quant. Biol. 52, 499-510

20 Heizmann, C. W. and Hunziker, W. (1991) Trends Biochem. Sci. 16, 98-103

21 Miller, R. J. (1991) Progress Neurobiol. 37, 255-285

22 Baimbridge, K. G., Miller, J. L. and Parkess, C. O. (1982) Brain Res. 239, 519-525

23 Heizmann, C. W. and Braun, K. (1992) Trends Neurosci. 15, 259-264

24 Cheung, W.-T., Richards, D. E. and Rogers, J. H. (1993) Eur. J. Biochem. 215, $401-410$

25 Strauss, K. I., Kuźnicki, Winsky, L. and Jacobowitz, D. M. (1994) Protein Express. Purif. 5, 187-191

26 Kuźnicki, J. Winsky, L. and Jacobowitz, D. M. (1994) Biochem. Mol. Biol. Int. 33, $713-721$

27 Winsky, L. and Kuźnicki, J. (1995) J. Neurochem., in the press

28 Maruyama, K., Mikawa, T. and Ebashi, S. (1984) J. Biochem. (Tokyo) 95, 511-519

29 Gross, M. D., Gosnell M., Tsarbooulos A. and Hunziker, W. (1993) J. Biol. Chem. 268, 20917-20922

30 Parmentier, M. (1990) Adv. Exp. Med. Biol. 269, 27-34

31 Gabrielides, C., McCormack, A. L., Hunt, D. F. and Christakos, S. (1991) Biochemistry 30, 656-662

32 Scharfman, A. E., Schwartzkroin, P. A. (1989) Science 246, 257-260

33 lacopino, A. M. and Christakos, S. (1990) Proc. Natl. Acad. Sci. U.S.A. 87. 4078-4082

34 Dalgarno, D., Klevit, R. E., Levine, B. A. and Williams, R. J.P (1984) Trends Pharmacol. Sci. 5, 266-271

35 Klee, C. B., (1991) Neurochem. Res. 16, 1059-65

36 Williams, R. J. P. (1992) Cell Calcium 13, 355-362 